\title{
Responsabilidade Civil do Estado Face às Ações de Vigilância Sanitária em Serviços de SaÚde ${ }^{(*)}$
}

\author{
THE CIVIL RESPONSIBILITY OF THE STATE IN FACE TO THE ACTIONS \\ OF SANITARY MONITORING IN HEALTH SERVICES
}

Patrícia Ferreira $^{(\star \star)}$

\section{RESUMO}

A saúde constitui um direito social, garantido mediante o desenvolvimento de políticas públicas sociais e econômicas. É dever do Estado, da coletividade e do indivíduo, adotar as medidas pertinentes a sua promoção e conservação. Na preservação dos interesses sociais e do direito à saúde, multiplica-se a cada dia a exigência legal de alvarás administrativos, licenças ou permissão para execução de obras ou prestação de serviços, com a obrigação correlata da entidade estatal de fiscalizar a observância da exigência legal e a execução da obra ou a prestação do serviço autorizado. Procurar-se-á, aqui, desenvolver a análise da matéria a partir de noções gerais sobre responsabilidade civil, sua relevância nos dias atuais, no que se diz pertinente ao Estado, para verificar, em seguida, como aspecto central, a responsabilidade civil do Estado face às ações de vigilância sanitária em serviços de saúde. A produção doutrinária pertinente ao tema específico ainda é pequena e insuficiente, não obstante a grande profundidade na abordagem do instituto jurídico da responsabilidade civil do Estado. E é justamente em tais estudos doutrinários, bem como na escassa jurisprudência sobre a questão, que se fixará o embasamento do presente trabalho.

\section{Palavras-chave}

Responsabilidade Civil do Estado; Vigilância Sanitária; Serviços de Saúde; Saúde Pública; Direito Sanitário.

(*) Trabalho apresentado para obtenção do título de especialista em Direito Sanitário na Fundação Oswaldo Cruz/ Escola Nacional de Saúde Pública Sérgio Arouca.

${ }^{* *}$ ) Bióloga, Especialista em Direito Sanitário e em Saúde Coletiva/Nigilância Sanitária, Inspetora da Vigilância Sanitária do Distrito Federal e Técnica da ANVISA/MS - Programa Nacional de Inspeção em Unidades Hemoterápica. E-mail:<ferreirasaude@yahoo.com.br>. 


\section{ABSTRACT}

The health constitutes a social right, guaranteed by the development of social and economical public politics. It is owe of the State, collectivity and of the individual to adopt the pertinent measures for your promotion and conservation. In the preservation of the social interests and of the right to the health, multiplies every day the legal demand of administrative permits, licenses or permission for execution of works or the installment of the authorized service. It will be sought, here, to develop the analysis of the matter starting from general notions about civil responsibility, your relevance in the current days, in what is said pertinent to the State, to verify, soon after, as central aspects, the civil responsibility of the State in face to the actions of Sanitary Surveillance in health services. The production pertinent doctrinaire to the specific theme is still small and insufficient, in spite of the great depth in the approach of the juridical institute of the civil responsibility of the State. And it is exactly in such studies doctrinaires, as well as in the scarce jurisprudence on the subject, that will notice the content of the present work.

\section{Key words}

Civil Responsibility of the State; Health Surveillance; Health Services; Public Health; Health Law.

\section{INTRODUÇÃO}

Longo foi o processo para a responsabilização civil do Estado, evoluindo primeiro da sua total irresponsabilidade, passando pelas teorias subjetivistas (que adotavam os princípios do direito civil apoiadas na idéia de culpa) até finalmente se alcançar o primado do risco administrativo. Todavia, seu grande avanço só se deu a partir da contribuição das teorias publicistas que surgiram da evolução da jurisprudência administrativa francesa, do seu agigantamento e da sua submissão aos princípios da legalidade e igualdade inerentes ao Estado Democrático de Direito. Daí por que se dizer que a responsabilidade é a marca fundamental do Estado contemporâneo.

No momento em que se rediscute o papel do Estado na sociedade moderna, buscando, conseqüentemente, estabelecer um equilíbrio entre a atividade estatal e a preservação da qualidade de vida da sociedade, tornam-se mais evidentes as responsabilidades do poder público, seja como agente seja como fiscal. Assim, o Estado, ente constituído para disciplinar as condutas sociais e manter a harmonia na sociedade, também se submete ao direito ao exercer seu poder de comando sobre a sociedade, sendo ele passível de responsabilização pelos danos que ocasionar aos cidadãos. 
$\mathrm{Na}$ amplitude do seu poder de polícia, o Estado, nas suas várias esferas, avoca para si o encargo de disciplinar e regulamentar atividades particulares, visando com isso à preservação de interesses coletivos na área da saúde, cumprindo-lhe ao mesmo tempo, ordenar e fiscalizar as obras e serviços que digam respeito a tais atividades.

Na preservação dos interesses sociais e do direito à saúde, multiplicase a cada dia a exigência legal de alvarás administrativos, licenças ou permissões para execução de obras ou prestação de serviços, com a obrigação correlata da entidade estatal de fiscalizar a observância da exigência legal e a execução da obra ou a prestação do serviço autorizado.

O instituto jurídico da responsabilidade civil do Estado é um tema atual, instigante e de grande relevância social, capaz de restabelecer a harmonia e o equilíbrio rompidos, obrigando o Estado a bem desempenhar suas funções, com diligência necessária para não ferir os direitos fundamentais assegurados na Constituição, sendo de fundamental importância para os profissionais das ciências jurídicas e da saúde.

Procurar-se-á, aqui, desenvolver a análise da matéria a partir de noçōes gerais sobre responsabilidade civil, no que se diz pertinente ao Estado, para verificar, em seguida, como aspecto central, a responsabilidade civil do Estado por danos causados aos cidadãos no desempenho de açōes de vigilância sanitária em serviços de saúde.

\section{RESPONSABILIDADE CIVIL DO ESTADO}

\subsection{Conceito}

A responsabilidade civil do Estado constitui-se na obrigação legal de indenizar os prejuízos causados aos administrados em razão do exercício de atividades públicas. O fundamento de tal responsabilidade é simples. $O$ Estado também é capaz de ocasionar danos, enquanto pessoa jurídica, sujeito de direitos e deveres, podendo esses danos ser provocados no exercício legal e legítimo de suas funçōes, sejam elas quais forem.

Os princípios fundamentais do instituto da responsabilidade foram primeiramente elaborados pelo direito privado, razão pela qual há uma tendência em chamar esse dever de indenizar, imputável ao Estado, de "responsabilidade civil do Estado". Embora para muitos publicistas persista essa denominação, há correntes que utilizam a expressão "responsabilidade extracontratual do Estado" para enfocar a responsabilidade estatal desvinculada da responsabilidade contratual.

A responsabilidade do Estado, embora originária da responsabilidade civil, governa-se hoje por princípios próprios, decorrentes da peculiar posi- 
ção do Estado face aos cidadãos, e seus parâmetros estão, definitivamente, estabelecidos na Constituição. Entretanto, a amplitude que lhe é imputada é uma aquisição relativamente nova, resultante de uma constante evolução doutrinária, antes de cristalizar-se constitucionalmente nos ordenamentos jurídicos dos Estados Democráticos de Direito.

$O$ anseio de obrigar o causador do dano a repará-lo inspira-se no mais elementar sentido de justiça, não podendo o Estado negá-lo ou ignorá-lo. 0 dano causado, seja por ato lícito ou ilícito do Estado, na figura de seus agentes, rompe o equilíbrio jurídico-econômico anteriormente existente. Há uma necessidade fundamental de se restabelecer esse equilíbrio, o que se procura fazer fixando-se uma indenização proporcional ao dano, quando impossível repor a situação ao estado em que se encontrava.

\subsection{Elementos da responsabilidade estatal}

Para que ocorra a necessidade de restabelecer a harmonia violada é preciso ter clara a obrigação do causador do dano em indenizar, que se faz identificando os elementos configurativos desta responsabilidade: sujeito ativo dessa relação jurídica é todo e qualquer cidadão, administrado, ou ainda qualquer pessoa jurídica, que venha a sofrer um dano. É o credor da obrigação, o lesado, o injustiçado. Sujeito passivo é o causador do dano, no caso, o Estado (pessoas jurídicas públicas ou empresas privadas prestadoras de serviços públicos, nos termos do $\S 6^{\circ}$ do art. 37 da Carta de 1988) que, por meio de seus agentes, direta ou indiretamente, tenham agido propiciando o dano.

O art. 37, § $6^{9}$ da Constituição Federal de 1988, dispõe que a Administração Pública será responsável pelos atos de seus agentes que, nesta qualidade, causarem danos a terceiros. A palavra agente compreende aquelas pessoas que, de uma forma ou de outra, regular ou irregularmente, quer em caráter permanente, quer em caráter transitório, se encontrem exercendo qualquer atividade inerente ao serviço público, e hábeis à produção de danos, pelos quais deve responder o Estado. É o sujeito passivo, portanto, o Estado que, por meio de seus agentes, estes atuando na qualidade de agentes estatais, vier a lesionar o patrimônio de terceiro.

Para ser indenizável, o dano, a princípio, deve corresponder à lesão de um bem juridicamente protegido, isto é, ter relevância jurídica, estar contido no âmbito de proteção da norma violada. Conseqüentemente, deve partir de um ato, ou fato antijurídico, ilegítimo, no sentido de que o ofendido não tenha o dever legal de suportá-lo.

Para se determinar quais os danos indenizáveis, oriundos de atos antijurídicos, o papel da norma é fundamental. Será esta que esclarecerá quais os valores, direitos e garantias a serem tutelados, quais são os bens e pessoas 
que se intenta proteger. Isto porque, para que haja uma ofensa a direito de alguém, é preciso que este direito esteja tutelado como tal.

O nexo de causalidade é o elo que une o fato ao dano. É a maneira pela qual se evidencia que o desdobramento daquele ato do sujeito ocasionou o dano. Portanto, o objeto do nexo de causalidade é demonstrar que em conseqüência daquele ato, praticado pelo Estado, é derivada a lesão a direito.

Já o nexo de imputação, ou seja, o fundamento pelo qual se imputa ao Estado a responsabilidade pelos danos que vier a causar a outrem, pauta-se na idéia do risco criado pelo desenvolvimento da atividade estatal. Deve-se ressaltar que, para os adeptos da corrente doutrinária subjetivista do Estado, este fundamento encontra-se na idéia do agir com culpa do agente causador do dano.

A responsabilidade civil estatal será elidida, no entanto, em determinadas situações, quando não houver nexo causal entre a conduta omissiva ou comissiva do agente do Estado e o dano suportado pelo particular. Esta exclusão de responsabilidade ocorrerá diante da força maior, do caso fortuito, do estado de necessidade e da culpa exclusiva da vítima ou de terceiro.

\section{AÇÕES DE VIGILÂNCIA SANITÁRIA EM SERVIÇOS DE SAÚDE}

Ao Sistema Único de Saúde compete, além de outras atribuiçōes, nos termos do art. 200 da Constituição Federal, executar as ações de vigilância sanitária, como função típica e exclusiva de Estado. A Lei n. 8.080/90, denominada Lei Orgânica da Saúde organiza o SUS e inaugura uma nova condição jurídico-formal para a Vigilância Sanitária, em seu $\S 1^{\circ}$ do art. $6^{\circ}$, ao defini-la como:

Conjunto de ações capazes de eliminar, diminuir ou prevenir riscos à saúde e de intervir nos problemas sanitários decorrentes do meio ambiente, da produção e da circulação de bens e da prestação de serviços de interesse da saúde, abrangendo:

1 - o controle de bens de consumo que, direta ou indiretamente, se relacionam com a saúde, compreendendo todas as etapas e processos, da produção ao consumo; e

II - o controle da prestação de serviços que se relacionam direta ou indiretamente com a saúde.(1)

(1) BRASIL. Lei n. 8.080, de 19 de setembro de 1990. Dispõe sobre as condiçōes para a promoção, proteçāo e recuperaçāo da saúde, a organização e o funcionamento dos serviços correspondentes e dá outras providências. Diário Oficial da República Federativa do Brasil, Brasília, DF, 20 de setembro de 1990. Seçãol, pt. I, p. 18055-9. 
Essa definição denota a abrangência das ações de Vigilância Sanitária e a sua missão de interferir na reprodução das condições econômico-sociais, ambientais e de vida, submetendo-se, portanto, aos princípios próprios do SUS, que consistem em atendimento integral, com prioridade para as atividades preventivas, sem prejuízo dos serviços assistenciais, participação da comunidade e descentralização.

O diploma legal básico orientador das ações sanitárias em serviços de saúde é o Decreto n. $77.052 / 76$ que dispõe sobre a fiscalização sanitária das condiçōes de exercício de profissōes e ocupaçōes técnicas e auxiliares diretamente relacionadas com a saúde e estabelece os elementos a serem considerados: capacidade legal do agente; adequação das condiçōes do ambiente onde se processa a atividade profissional para a prática de ações que visem à promoção, proteção e recuperação da saúde; existência de instalações, equipamentos e aparelhagem indispensáveis e condizentes com as suas finalidades, e em perfeito estado de funcionamento; meios de proteção capazes de evitar efeitos nocivos à saúde dos agentes, clientes, pacientes, e dos circunstantes; métodos ou processos de tratamento dos pacientes, de acordo com critérios científicos e não vedados por lei e técnicas de utilização de equipamentos.

Especialistas em vigilância sanitária de São Paulo, em sua análise: Avanços e recuos: um caso de São Paulo, apontam que as ações de vigilância sanitária em serviços de saúde não se configura tarefa fácil:

"Em um país com tradição clientelista e autoritária como o Brasil, estabelecer cronogramas de adequaçōes, bem como outras providências que visem a corrigir impropriedades técnicas, em estabelecimentos integrantes do sistema público de saúde que assistam a população trabalhado$\mathrm{ra}$, as massas populares, enfim, a população em geral, era - e continua sendo - tarefa dificílima, já que a operação das políticas públicas de saúde, também, destina-se a manter coesa ( $\mathrm{sic}$ ) as bases de sustentação social das forças políticas dirigentes"(2).

Por serem de relevância pública, as ações e os serviços de saúde ficam submetidos à regulamentação, fiscalização e controle do poder público. Assim sendo, uma vez atribuído ao Poder Público o controle das ações e dos serviços de saúde, tem ele integral dominação dos mesmos, sendo, portanto, indispensável a existência de órgãos e entidades para fazerem valer as normas de ordem pública relativas à saúde.

\section{RESPONSABILIDADE CIVIL DO ESTADO FACE ÀS AÇÓES DE VIGILÂNCIA SANITÁRIA EM SERVIÇOS DE SAÚDE}

Uma das principais funçōes do Estado democrático moderno é proteger e promover a saúde e o bem-estar dos cidadãos. Nesse sentido, cabe ao

(2) MENEZES, R. F. de; SILVA, Z. M. da; HORIE, M. H. Y. S. Avanços e recuos: um caso de São Paulo. In:MARQUES, Maria Cristina et al. (Org.). Casos e fatos da vigilância sanitária sobre a saúde da sociedade. São Paulo: Sobravime; CVS, 2002. p. 70. 
Estado zelar pelos interesses coletivos, intervindo nas atividades particulares, disciplinando-as, quando põem em risco a saúde pública.

Tem-se hoje à disposição uma grande variedade de produtos e serviços de saúde que facilitam e estendem a sobrevida humana; mas, grande parte dessas tecnologias são potencialmente iatrogênicas, o que faz com que a qualidade, eficácia, segurança e a racionalidade em seu uso ou consumo tornem-se questōes críticas para a saúde pública e uma preocupação para a sociedade, colocando desafios para os órgãos responsáveis pelo controle sanitário.

As ações de vigilância sanitária constituem tanto uma ação de saúde quanto um instrumento de organização econômica da sociedade. A experiência histórica tem demonstrado que o mercado é incapaz de se auto-regular para garantir os interesses sanitários da coletividade pela própria incapacidade do modo de produção - centrado na forma mercadoria - que tende a subtrair direitos fundamentais à saúde e à vida. $O$ reconhecimento da vulnerabilidade do consumidor no mercado de consumo de bens e serviços de saúde, gradativamente potencializada pela assimetria de informação, sustenta a obrigatoriedade da regulação das práticas do mercado no interesse da saúde humana(3).

A responsabilidade do Estado face às ações de vigilância sanitária fundamenta-se na sua atividade administrativa ou no descumprimento do seu dever de agir, comportamentos estatais comissivos ou omissivos, que venham causar prejuízos ao cidadão. Corroborando os ensinamentos acima, observa com propriedade o Promotor de Justiça do Ministério Público do Estado de São Paulo, José Marcelo Menezes Vigliar.

"O art. 197 da CF, ao tratar da fiscalização e controle das açōes e serviços de saúde, deixa muito claro que não somente as atitudes comissivas serão punidas, caso contrariem a importância que a Constituição empresta às ações e serviços de saúde; também as omissões do poder público merecem o mesmo rigor, seja para fiscalizar o desempenho de quem venha realizando as referidas açōes e/ou serviços de saúde (o Estado diretamente, ou por terceiros, mesmo que pessoa física ou jurídica de direito privado), seja para controlá-la e viabilizá-la na forma desejada pela Constituição, que reconheceu esta obrigação que é do Estado"(4).

Todavia, a questão da responsabilidade civil do Estado ganha contornos mais acentuados quando se busca aplicar a consagrada teoria objetiva para os casos de prejuízos ocasionados aos cidadãos em razão da inação

(3) COSTA, Ediná Alves. Vigilância sanitária:proteção e defesa da saúde. São Paulo: Sobravime; Hucitec, 2000. p. 381-384.

(4) VIGLIAR, José Marcelo Menezes. Saúde pública e improbidade administrativa. In:ARANHA, Márcio lorio; TOJAL, Sebastião Botto de Barros (Orgs.). Curso de Especialização à distância em Direito Sanitário para Membros do Ministério Público e da Magistratura Federal. Brasília: UnB, 2002. p. 425. 
ou omissão do Poder Público na realização adequada dos serviços que the competem em razão do seu poder-dever de agir.

Assim, enquanto uns entendem que a responsabilidade objetiva do Estado se faz presente em qualquer situação, seja por comissão ou omissão, outros entendem que a Constituição Feredal de 1988 albergou apenas a responsabilidade objetiva derivada de atos positivos, devendo-se perquirir, nos outros casos, sobre a responsabilidade subjetiva.

Daí, grandes divergências tanto no âmbito doutrinário quanto jurisprudencial têm surgido nesse sentido. Sobre este tema digladiam-se assim duas correntes principais, conforme veremos abaixo:

\subsection{Posições doutrinárias}

\subsubsection{Corrente objetiva}

Para os adeptos desta corrente, a CF/88 consagra em definitivo a teoria do risco administrativo, em que se assenta a responsabilidade objetiva do Estado, positivando-a expressamente em seu art. 37, $\S 6^{\circ}$, dispondo que:

as pessoas jurídicas de direito público e as de direito privado prestadoras de serviços públicos responderão pelos danos que seus agentes, nessa qualidade, causarem a terceiros, assegurado o direito de regresso contra o responsável nos casos de dolo ou culpa.(5)

Yussef Said Cahali, adepto desta corrente, ao expor o seu entendimento, assim preceituou:

"[...] a responsabilidade implica a assunção de responsabilidade pelo risco criado pelas atividades impostas ao órgão público; ao nível da (sic) responsabilidade objetiva - e, conseqüentemente, da teoria do risco criado pela atividade administrativa - descarta-se qualquer indagação em torno da falha do serviço ou da culpa anônima da administração. Em vão, portanto, tentar-se uma superação dessas colocaçōes antagônicas, buscando sua composição através de certas especificações artificiais ou decomposiçōes da teoria do risco"(6).

$\mathrm{Na}$ mesma linha de raciocínio, Celso Ribeiro Bastos e Hely Lopes Meirelles, analisam a responsabilidade do Estado, ensinando que tal entendimento já se encontra sedimentado atualmente, não havendo, portanto, razōes para se questionar sobre o elemento subjetivo da culpa entre o dano e o comportamento que o provocou, defendendo a tese da responsabilidade objetiva $^{(7)}$.

(5) BRASIL. Constituição. Constituição da República Federativa do Brasil. Brasília, DF: Senado, 1988.

(6) CAHALI, Yussef Said. Responsabilidade civil do Estado. 1. ed. São Paulo: Malheiros Ed., 1982. p. 34.

(7) VENDRAMEL, Aparecida. Responsabilidade extracontratual do Estado. 1. ed. São Paulo: Themis, 2000.p. 58-59. 
Portanto, o Estado ou quem o represente, deve responder pelos eventuais prejuízos causados ao cidadão, independente da existência de dolo ou culpa, prescindindo assim da análise dos elementos subjetivos, sendo relevante tão-somente o nexo de causalidade entre o funcionamento do serviço público e o dano sofrido pelo administrado.

\section{Odete Medauar acrescenta:}

"Como nem sempre é possível identificar o agente causador do dano, nem demonstrar o dolo ou culpa, melhor se assegura os direitos da vítima através da aplicação da responsabilidade objetiva ao Estado"(8).

Todavia, para os adeptos da corrente objetivista, não é apenas a ação positiva do Estado que pode produzir danos e gerar direito à indenização fundada no risco administrativo, mas também a sua omissão que pode significar negligência, inatividade, desídia, inércia ou a não observância de um dever de agir ou da prática de certo ato que juridicamente se devia realizar.

Pode-se dizer assim que a responsabilidade do Estado, em face de condutas omissivas, tem como pressuposto a responsabilidade extracontratual (aquiliana) resultante do inadimplemento normativo, ou melhor, é a lesão a um direito, perda da situação juridicamente protegida.

Partindo-se desse pressuposto, um dano causado ao administrado pode ocorrer simplesmente em virtude da recusa ou inadimplemento voluntário de uma obrigação pelo Estado que não se tornou impossível. Trata-se daquelas hipóteses em que a Administração Pública poderia ter cumprido o seu papel (dever legal), mas não o fez (omitiu-se) porque não lhe era conveniente ou porque não empregou os esforços necessários (suficientes).

A omissão do Estado pode assim denotar culpa in omittendo ou culpa in vigilando, podendo causar prejuízos aos administrados, à administração e ao próprio agente público responsável, pois como assevera Cretella Júnior:

"[...] se se cruza os braços ou não se vigia, quando deveria agir, o agente público omite-se, empenhando a responsabilidade do Estado por inércia ou incúria do agente"(9).

Isso, contudo, não significa dizer que a responsabilidade objetiva deva ser desprezada, passando-se a aplicar a teoria subjetiva nas hipóteses de danos causados aos particulares por atos omissivos do Estado. Na realidade, é perfeitamente admissível que, agindo com dolo ou culpa, um agente estatal venha a omitir-se acarretando a violação de uma norma jurídica protetora de interesses alheios ou de um direito subjetivo individual, e nem por isso a teoria objetiva deixa de ter validade.

(8) MEDAUAR, Odete. Direito administrativo modemo. 4. ed. São Paulo: Ed. Revista dos Tribunais, 2000. p. 252.

(9) CRETELLA JUNIOR, José. Tratado de direito administrativo. 1. ed. Rio de Janeiro: Forense, p. 210 apud GONÇALVES, Carlos Roberto. Responsabilidade civil: de acordo com o novo Código Civil (Lei $n$. 10.406, de 10.1.2002). 8. ed. São Paulo: Saraiva, 2003. p. 179. 
A peculiaridade com que se reveste a responsabilidade objetiva da Administração Pública por atos omissivos é que, ao contrário daquela derivada de atos comissivos onde basta tão-somente a demonstração da ação positiva do Poder Público e dos danos causados ao particular para que se configure o nexo causal, é preciso se perquirir, no caso concreto, se era exigido do Estado um dever geral de cautela que foi desprezado, já que inexiste um ato comissivo para ser demonstrado.

De fato, o importante a se notar nesta hipótese de responsabilidade em particular é que o nexo causal deve ser mantido. Para tanto, não basta à configuração da responsabilidade estatal a simples relação entre a ausência do serviço (omissão estatal) e o dano sofrido. É necessário demonstrar que era obrigatória a execução desse serviço no caso concreto e que, em razão da conduta negativa do agente que deixou de realizá-lo quando the era obrigatório por força de lei, foram ocasionados danos ao particular. Se tivesse agido, ao invés de manter-se inerte quando lhe era devido, os malefícios não teriam se produzido (ou seriam minorados).

Assim, uma vez existindo esse dever legal de atuação e omitindo-se o ente público frente ao mesmo, vindo o administrado a sofrer um dano em razão dessa ação negativa, qualquer que seja a hipótese, justifica-se a adoção da responsabilidade objetiva já que o nexo causal, imprescindível para a aplicação da teoria, foi devidamente preenchido. Daí ser necessária a análise do caso concreto pelo magistrado, que verificará a atuação ou dever de vigilância do Estado, para que seja civilmente responsabilizado pelos danos causados ao particular.

A responsabilidade objetiva por atos omissivos decorre assim do descumprimento da lei que deixou de ser observada na conformidade de seu comando. Quando a prestação do serviço desvia-se do regime legal a ele imposto, deixando o Estado de prestá-lo no momento correto e/ou da forma devida, verifica-se sua responsabilidade, devendo então ser composto o dano decorrente dessa atuação da Administração Pública.

Da própria dicção do art. $37, \S 6^{\circ}$, da CF, vê-se claramente que é irrelevante para que o administrado - na posição de terceiro prejudicado - venha a obter o reconhecimento da responsabilidade extracontratual do Estado, se perquirir se este último obrou com culpa ou dolo. O que se requer de fato é a existência dos pressupostos para a aplicação da teoria objetiva, sejam eles, o nexo causal entre a conduta omissiva do Poder Público (omissão essa que não poderia ter se verificado na hipótese concreta) e o dano efetivamente sofrido pelo administrado (não meramente circunstancial ou potencial).

O texto constitucional não diverge desse entendimento na medida em que apenas faz menção às qualidades do agente causador do dano (estar incumbido de autoridade proveniente do poder público) e não às características de sua conduta (se comissiva ou omissiva, lícita ou ilícita) para a confi- 
guração da responsabilidade do Estado, decorrendo essa do simples funcionamento ou falta dos seus serviços.

O aspecto subjetivo só ganha relevância no que se refere ao direito de regresso do Estado contra seus agentes, sejam eles integrantes das pessoas jurídicas de direito público ou das pessoas de direito privado prestadoras de serviço público. Pode-se dizer assim que no dispositivo constitucional em análise estão compreendidas a responsabilidade objetiva do Estado e a responsabilidade subjetiva do agente.

O Estado assume assim, por força da Carta Magna, os danos decorrentes de sua atividade bem como de sua falta, sendo a ele aplicada a teoria dos riscos, segundo a qual, todo aquele que se propōe a desenvolver qualquer atividade tem a conseqüente obrigação de responder pelos prejuízos causados, seja em razão de ação ou omissão, não se questionando aí se concorreu ou não com culpa ao evento danoso (desvincula-se o dever de reparar o dano da idéia de culpa).

Daí, no que respeita à responsabilidade extracontratual do Estado, pode-se dizer a regra geral é a da responsabilidade objetiva, fundada na teoria do risco da atividade, constante no art. $37, \S 6^{\circ}, \mathrm{CF}$, insuscetível de excluir do Estado o dever de indenizar, mesmo quando ocorrer omissão.

\subsubsection{Corrente subjetiva}

Para os subjetivistas, tratando-se de conduta comissiva do Estado, a responsabilidade é sempre objetiva porque tal é fundada na teoria do risco. Assim, mesmo quando o Estado assume alguma atividade para satisfazer a necessidade dos seus administrados, se o Poder Público vier a ocasionar um dano, será obrigado a ressarci-lo sem indagação de culpa.

Para haver a responsabilização do Poder Público por atos omissivos, é mister indagar sobre a culpa por negligência, imprudência ou imperícia, sendo aplicada na espécie a teoria subjetiva.

Vários são seus seguidores, dentre eles destacando-se Celso Antônio Bandeira de Mello ao afirmar que:

"Quando o dano foi possível em decorrência de uma omissão do Estado (o serviço não funcionou, funcionou tardia ou ineficientemente) é de aplicar-se a teoria da responsabilidade subjetiva. Com efeito, se o Estado não agiu, não pode, logicamente, ser ele o autor do dano. $E$, se não foi o autor, só cabe responsabilizá-lo caso esteja obrigado a impedir o dano. Isto é: só faz sentido responsabilizá-lo se descumpriu dever legal que the impunha obstar ao evento lesivo"(10).

(10) MELLO, Celso Antônio Bandeira de. Curso de direito administrativo. 16. ed. São Paulo: Malheiros Ed., 2003. p. 871-872. 
Nesse mesmo sentido Lúcia Valle Figueiredo sustenta:

"[...] ainda que consagre o texto constitucional a responsabilidade objetiva, não há como se verificar a adequalibilidade da imputação ao Estado na hipótese de omissão, a não ser pela teoria subjetiva. Assim é porque, para se configurar a responsabilidade estatal pelos danos causados, há de se verificar (na hipótese de omissão) se era de se esperar a atuação do Estado [...] se [...] omitiu-se, há de se perquirir se havia o dever de agir. Ou, então, se a ação estatal teria sido defeituosa a ponto de se caracterizar a insuficiência da prestação do serviço"(11).

Também comunga dessa corrente Maria Sylvia Zanella Di Pietro ao afirmar que:

"a omissão na prestação do serviço tem levado à aplicação da teoria da culpa do serviço público ("faute du service"); é a culpa anônima, não individualizada; o dano não decorreu de atuação de agente público, mas de omissão do poder público"(12).

Vê-se assim que, o importante para os adeptos desta corrente é se analisar o aspecto subjetivo da conduta do agente público (prova de culpa ou dolo), para só então se proceder à responsabilização do Estado.

Ainda de acordo com Celso Antônio Bandeira de Mello, a omissão pode ser uma condição para que outro evento cause o dano, mas ela mesma - a omissão - não pode produzir o evento danoso. A omissão poderá ter condicionado sua ocorrência, mas não o causou. Causa é o fator que positivamente gera um resultado. Condição é o evento que não ocorreu, mas que, se houvera ocorrido, teria impedido o resultado ${ }^{(13)}$.

Assim, segundo os subjetivistas, o art. $37, \S 6^{\circ}$, da CF reporta-se somente a comportamentos comissivos do Estado, pois só uma atuação positiva pode causar (produzir) um evento. Já na hipótese de omissão, por impossibilidade de se provar a conduta omissiva do Estado de forma objetiva, dever-se-á apelar para a responsabilidade subjetiva, verificando-se, destarte, se houve ausência de prestação devida ou, também - embora tenha havido tal prestação - sua deficiência.

Uma crítica que pode ser levantada contra a responsabilidade subjetiva é que o ônus da prova pertence à vítima, constituindo um empecilho à reparação do dano. Permitir que o particular lesado pela omissão ilícita do Estado, percorra os mais difíceis caminhos processuais na tentativa de provar a culpa ou dolo do agente público, é afrontar o princípio da igualdade. $\mathrm{Na}$ lição de Celso Antônio Bandeira de Mello: "Razoável, portanto, que nestas hipóteses ocorra inversão do ônus da prova."(14)

(11) FIGUEIREDO, Lúcia Valle. Curso de direito administrativo. 2. өd. São Paulo: Malheiros Ed., 1995. p. 179.

(12) DI PIETRO, Maria Sylvia Zanella. Direito administrativo. 10. ed. São Paulo: Atlas, 1999. p. 415.

(13) MELLO, Celso Antônio Bandeira de. op. cit.p. 873.

(14) Id. Ibid. p. 874. 


\subsection{Natureza da responsabilidade em vigilância sanitária}

A norma sanitária, apoiada pela norma constitucional, faz nascer para o administrado o acesso aos serviços de saúde prestados de maneira adequada e eficiente, ao mesmo tempo em que gera para o poder público o dever de zelar pelas condições deste serviço prestado. Portanto, estando a vigilância sanitária obrigada a eliminar, diminuir ou prevenir o risco sanitário, se não o fizer ou o fizer de forma inadequada ou até mesmo adequada e, em conseqüência de sua ação sobrevier dano, deve existir a reparação do mesmo.

Assim, teremos estabelecida a relação processual que se formará em conseqüência do descumprimento do estatuído na norma constitucional, onde a vigilância sanitária tem o poder-dever de agir, figurando nessa relação, como sujeito passivo, o Estado.

A base legal da norma primária dispositiva é o dever de cumprimento das competências da vigilância sanitária, expressos na CF, na Lei n. 8.080/90 (Lei Orgânica da Saúde) e nas demais legislações específicas que dispõem sobre ações sanitárias e art. 37, § 6 (Responsabilidade do Estado).

Já a da norma secundária, assenta-se no inciso XXXV do art. $5^{\circ}$ da CF que dispōe: "a lei não excluirá da apreciação do poder judiciário lesão ou ameaça a direito."

Quando o Estado intervém em atividades de particulares, busca evitar que a possível nocividade de produtos e serviços prejudique a saúde dos cidadãos. A vigilância sanitária deve, ante suspeita ou alegação de nocividade, ordenar a suspensão da fabricação e venda de produtos/ equipamentos e interdição de serviços nocivos à saúde humana, embora até tenham registro/autorização do órgão sanitário competente tais como: medicamentos e vacinas sem eficácia, hemoderivados contaminados por vírus, hospitais funcionando em desacordo com a legislação sanitária vigente quanto à estrutura e procedimentos etc. Quando o órgão sanitário aprova e libera para uso produtos e serviços que contrariem as normas técnicas e científicas até então aceitas, cabe ao Estado responder por esta conduta comissiva.

O Estado, em não se preocupar com o devido aparelhamento, tanto dos serviços de saúde quanto da vigilância sanitária, que o controla e fiscaliza, incorre em violação flagrante de direito fundamental, podendo ser invocado judicialmente a responder também pelos danos de sua omissão. A responsabilidade do Estado por atos omissivos trata-se assim, na maioria dos casos, de situaçōes que poderiam ter sido previstas e evitadas pela autoridade competente que se omitiu em proceder conforme os ditames legais. Convém ressaltar a colocação dos especialistas em saúde pública: 
"[...] 'a tragédia de Caruaru', em março de 1996, ao passo que contribuiu para fazer avançar a vigilância sanitária de serviços de saúde, também contribuiu decisivamente no processo de incorporação gradativa à consciência popular da exigência de órgãos de vigilância sanitária atuantes e - mais do que isso - presentes e firmes: as mortes dos pacientes renais crônicos na unidade de diálise de Caruaru, que foram informadas detalhadamente pela televisão durante dias, é de crer, não contribuíram para formação de juízo de valor sobre as responsabilidades pelo ocorrido, mas geraram algo muito mais positivo, ou seja, a idéia difusa de que o poder público deve fiscalizar os estabelecimentos de saúde e fiscalizar-se, quando for o caso"(15).

Os eventos negativos de maior repercussão tendem a impulsionar medidas normativas e, ou concretas, para melhoria do elemento incriminado. As investigações apontaram a causa dos óbitos: a água empregada na realização da hemodiálise continha toxina letal proveniente dos mananciais contaminados. Nesse sentido, após a tragédia que se verificou em Caruaru, o Ministro da Saúde considerou ser necessário estabelecer um novo Regulamento Técnico norteador do funcionamento dos Serviços de Terapia Renal Substitutiva.

Um extenso levantamento na literatura científica mundial sobre a incidência e prevalência de hepatites $\mathrm{C}$ e $\mathrm{B}$ em pacientes hemodialisados, aponta a concreta possibilidade de indequaçōes na execução de procedimentos no interior dos ambientes de terapia. Assim, pode-se considerar que serviços de alto risco como os serviços de terapia renal e serviços hemoterápicos devem ser avaliados e inspecionados, no mínimo, anualmente.

Em 1996 vem ao conhecimento do público, de modo contundente, a degradação a que chegou o subsistema público de saúde do país. A doutora Ediná Costa em sua análise sobre a conformação histórica da vigilância sanitária no Brasil, nos relata:

"[...] Neste ano, em pouco mais de dois meses, faleceram 99 dos 329 idosos internados em clínica contratada pelo SUS no Rio de Janeiro, sob alegações de que eram "pacientes terminais". Pôde-se verificar a ausência de quaisquer ações de vigilância sanitária no estabelecimento, que os pacientes foram vítimas de maus tratos (sic), segundo dolorosos depoimentos de sobreviventes, avaliando-se que apenas $7 \%$ dos internados foram considerados sem possibilidades terapêuticas. Só o escândalo mobilizou os poderes públicos para inspecionar os estabelecimentos conveniados com o SUS, encontrando-se irregularidades incompatíveis com princípios éticos e com a dignidade da pessoa humana. Essa clínica, denominada Santa Genoveva, foi fechada e

(15) MENEZES, R. F. de; SILVA, Z. M. da; HORIE, M. H. Y. S. op. cit., p. 21-71. 
outras 16 interditadas. [...] Ainda neste ano, entre agosto e setembro, 18 pessoas morreram em decorrência de acidentes tromboembólicos pelo uso de soro contaminado do Laboratório Endomed, desta vez em hospitais da rede privada. Houve, ainda, a comovente epidemia de mortes de 72 bebês, em maternidades do Rio de Janeiro, em apenas um mês - janeiro de 1998 - assinalando o ápice de um fenômeno que vinha sendo observado em menor grau, em várias partes do país, pelo menos desde o ano de 1966"(16).

O Estado não foi prudente na preparação das ações preventivas e vidas humanas pagaram por essa conduta. A responsabilidade por omissão pode ser atribuída a quem tinha o dever de impedir o resultado, desta forma, segundo o Professor Luiz Carlos Nemetz.

"A responsabilidade civil é solidária dos órgãos e entidades que integram a rede regionalizada e hierarquizada que constituem o Sistema Único de Saúde. Ou seja: a União, o estado e o município. Estes entes têm o chamado police power e não podem negligenciar o uso desta prerrogativa legal. Assim, todos estes entes, ou cada um deles, pode ser demandado por parte daquele que suporta ou suportou o dano"(17).

Para melhor entendimento do conceito de omissão aqui empregado, convém citar a lição de Aparecida Vendramel sobre o significado de omissão, caracterizando-a como "tomada de posição". Segundo a autora "tomase posição para agir ou para não agir, inclusive na diuturnidade da vida. Se omissão é 'tomada de posição', então omissão é conduta, é ação, e, embora ação negativa, de ação se trata"(18).

Nesse sentido, pode-se dizer que a responsabilidade civil do Estado nas ações sanitárias (comissivas e omissivas) será sempre objetiva, já que, no caso específico, existe um dever legal de agir de forma preventiva e até mesmo repressiva, bastando que fique configurado o nexo entre a sua conduta e o dano gerado.

Desse modo, quando a lei cria o dever do ente público de controlar e fiscalizar os serviços de saúde, executando ações sanitárias, estará estabelecendo no pólo oposto o direito do usuário a ter um sistema fiscalizatório eficiente que realmente o proteja de qualquer lesão ao seu patrimônio. A efetividade do direito à saúde tem de passar inquestionavelmente pela materialização e pelo exercício da cidadania com fundamento na vida com dignidade da pessoa humana.

Em contrapartida, para o Estado, é melhor investir em ações sanitárias preventivas, a ter que reparar os danos causados aos cidadãos.

(16) COSTA, Ediná Alves. op. cit., p. 356-357.

(17) NEMETZ, Luiz Carlos. Epidemia de dengue - responsabilidade civil. Revista Jurídica Consulex, Brasília, ano 6, v. 124, p. 31, mar. 2002.

(18) VENDRAMEL, Aparecida. op. cit., p. 115. 


\subsection{Responsabilidade estatal na jurisprudência brasileira}

Desde períodos remotos nossa jurisprudência acolhe a responsabilidade do Estado. O judiciário brasileiro sempre esteve vigilante em assegurar a obrigação estatal. Segundo Seabra Fagundes:

"É doutrina já firmada em nossa jurisprudência, copiosa e persistente, a responsabilidade civil do Estado pelo dano causado ao direito de particulares pela administração pública, responsabilidade que se resolve na indenização de perdas e danos causados"(19).

Conforme noticia Alexandre de Moraes, a questão da dicotomia da responsabilidade estatal já foi decidida pelo Supremo Tribunal Federal, ao afirmar que:

"A teoria do risco administrativo, consagrada em sucessivos documentos constitucionais brasileiros desde a Carta Política de 1946, confere fundamento doutrinário à responsabilidade civil objetiva do Poder Público pelos danos a que os agentes públicos houverem dado causa, por ação ou por omissão. Essa concepção teórica, que informa o princípio constitucional da responsabilidade civil objetiva do Poder Públi$\mathrm{co}$, faz emergir, da mera ocorrência de ato lesivo causado à vítima pelo Estado, o dever de indenizá-la pelo dano pessoal e/ou patrimonial sofrido, independentemente de caracterização de culpa dos agentes estatais ou de demonstração de falta do serviço público. Os elementos que compõem a estrutura e delineiam o perfil da responsabilidade civil objetiva do Poder Público compreendem (a) a alteridade do dano, (b) a causalidade material entre o eventus damni e o comportamento positivo (ação) ou negativo (omissão) do agente público, (c) a oficialidade da atividade causal e lesiva, imputável a agente do Poder Público, que tenha, nessa condição funcional, incidido em conduta comissiva ou omissiva, independentemente da licitude, ou não, do comportamento funcional (RTJ 140/636) e (d) a ausência de causa excludente da responsabilidade estatal (RTJ 55/503 - 71/99 - 91/377 - 99/1155 — 131/417)"(20).

A maioria das decisões de nossos tribunais fundamenta-se na regra constitucional da responsabilidade objetiva do Estado e conseqüente reparação, tanto nos casos de típica omissão, quanto nos casos de falta de presteza de seu agente. Até mesmo quando haja ação, mas sendo ela insuficiente, caracteriza-se a omissão geradora da responsabilidade civil do Estado.

Não obstante em grande número de julgados, apesar da invocação da responsabilidade objetiva, o que fazem é aplicar a teoria da responsabilida-

(19) FAGUNDES, Seabra. Revista dos Tribunais, 1972. p. 205-206 apud MELLO, Celso Antônio Bandeira de. op. cit., p. 895.

(20) MORAES, Alexandre de. Direito constitucional. 5. ed. São Paulo: Atlas, 1999. p. 327. 
de subjetiva em sua modalidade "falta do serviço" (ou "culpa de serviço"). 0 exame dos fundamentos das decisões comprova que invocam uma teoria, declarando-a acolhida pelo Texto Constitucional, mas fundamentam-se em outra"(21).

Especificamente quanto à responsabilidade civil face às ações de vigilância sanitária em serviços de saúde, tem-se observado que a jurisprudência ainda é incipiente. Quando o Estado responde civilmente, poucas vezes é citado em decorrência de ação sanitária (controle, fiscalização). A ausência de julgados nos tribunais brasileiros demonstra que os casos de danos causados pelo Estado no âmbito da vigilância sanitária, raras vezes chegam ao Judiciário.

Nesse diapasão é oportuno transcrever a ementa de julgamento da Apelação Cível que teve como Relator o Juiz Ricardo Regueira da $2^{a}$ Região do Tribunal Federal.

“Ementa: DEVER GENÉRICO DA UNIÃO FEDERAL E DO ESTADO DO RIO DE JANEIRO DE ZELAR PELA SAÚDE. PRELIMINAR DE FALTA DA AÇÃO PRINCIPAL QUE SE REJEITA.

(...) - A União Federal em (sic) a responsabilidade objetiva de fiscalizar e o Estado do Rio de Janeiro em operalizar (sic) os hospitais onde ocorrem as transfusões de sangue.

- É dever da União e do Estado zelar pela saúde das pessoas, a alegada falta de material para realizar exames no sangue estocado, configura negligência para com a saúde da população.

- Apelação e remessa necessária conhecidas e improvidas" (TFR, 1ํㅡ. T., AC

n. 140.375, Rel. Juiz Ricardo Regueira, j. 20.10.1999, DJU, 25.4.2000).(22)

Deve-se observar que o Juiz falou em "negligência" — referência à culpa - para caracterizar a responsabilidade estatal, que deveria ser objetiva, o que demonstra o despreparo e a insegurança da magistratura, conforme já descrito acima por Celso Antônio Bandeira de Mello, como um erro comum em nossos tribunais.

\section{CONCLUSÃO}

A Vigilância Sanitária é uma das formas mais complexas de Saúde Pública, pois suas ações de natureza eminentemente preventiva perpassam todas as práticas médico-sanitárias: promoção, proteção, recuperação e reabilitação da saúde. Além disso, atua sobre fatores de risco associados a

(21) MELLO, Celso Antônio Bandeira de. op. cit., p. 897.

(22) BRASIL.Tribunal Regional Federal. Região, 1. civil. Dever genérico da União Federal e do Estado do Rio de Janeiro de zelar pela saúde. Apelação Cível n. 140.375, Rel. Juiz Ricardo Regueira, j. 20.10.1999, DJU, 25 de abril de 2000. 
produtos, insumos e serviços relacionados com a saúde, o ambiente e o trabalho, com a circulação internacional de cargas e pessoas.

A Lei que organiza o Sistema Único de Saúde (Lei n. 8.080/90) define o papel e a abrangência da Vigilância à Saúde, percebendo-se em seu conteúdo a nítida intenção de transformar a Vigilância Sanitária em um instrumento de defesa da vida das pessoas. Claro está que uma das principais características das sociedades modernas é o consumo sempre crescente de mercadorias, bens e serviços, inclusive de produtos de interesse sanitário, de tecnologias médicas e de serviços de saúde, estando esse consumo distante das reais necessidades das pessoas, visto que não se baseia em escolhas livres e conscientes, mas num sistema de necessidades determinado por toda a organização social.

$\mathrm{Na}$ dinâmica contraditória e complexa desses processos são gerados muitos riscos e danos à saúde do indivíduo e da coletividade e as ações de vigilância sanitária se inserem no âmbito das relações sociais de produção e consumo, onde se origina a maior parte dos problemas de saúde sobre os quais é preciso o Estado intervir. Existe assim, a necessidade de regulação das relações de produção e consumo, onde se utilizem os instrumentos adequados de controle e fiscalização para proteger a saúde de toda a coletividade, reconhecendo-se a vulnerabilidade do cidadão. E caso o Estado gere dano, produzindo o evento lesivo, deve-se aplicar o instituto jurídico da responsabilidade. A própria noção do Estado de Direito postula essa solução. Tudo isso dentro de um sistema de garantias constitucionais onde o Estado tem como elemento fundamental a preservação da vida e a saúde dos cidadãos.

Assim como os princípios norteadores do Estado Democrático de Direito representam uma conquista dos movimentos revolucionários contra a opressão do absolutismo, também a Responsabilidade do Estado, na forma como hoje lhe é imputada nos ordenamentos jurídicos dos Estados Democráticos de Direito, é resultante de uma evolução doutrinária e normativa necessárias, face às circunstâncias históricas com as quais se defrontou a humanidade.

O atual administrado, consciente de sua posição, não aceita mais as explicaçōes em torno de descasos, desconsiderações ou desleixos do poder público. É justo que ao provimento estatal imperfeito corresponda a necessária responsabilização do Estado e que o dever ressarcitório the seja imposto, de modo a restaurar o equilíbrio social rompido pelo ato danoso.

As questões que envolvem a responsabilidade civil do Estado são muito complexas e ensejam diversas discussões doutrinárias e conflitos jurisprudenciais. Sobre esse tema digladiam-se assim duas correntes principais: uma que considera objetiva a responsabilidade do Estado, mesmo nos casos de omissão, e outra que, para essas hipóteses em especial, aceita 
tão-somente a aplicação da teoria subjetiva descartando-se totalmente a adoção da primeira, que só teria incidência em danos causados por atos comissivos.

A temática sobre a responsabilidade civil do Estado face às ações de vigilância em serviços de saúde ainda é incipiente na doutrina e jurisprudência brasileiras, muito embora a questão da responsabilidade do Estado seja amplamente discutida há tempos.

A regra jurídica que responsabiliza o Estado pelos danos que seus agentes, nessa qualidade, causarem a terceiros, não excepciona, não biparte a responsabilidade do Estado em objetiva, na ação, e subjetiva, na omissão. Se o Documento Máximo da Nação não excepciona, não cabe ao intérprete excepcionar, utilizando-se de uma interpretação extensiva para reviver teorias outras que não a abrangida pela Constituição.

A inércia do Estado, abstendo-se de realizar açōes sanitárias a que por lei está obrigado, não raras vezes termina por lesar o patrimônio jurídico individual, material ou moralmente. Portanto, já não é mais digno de discussão o dever que incumbe ao Estado de responder pelos prejuízos causados por sua inação, objetivamente, como determinado pelo preceito constitucional. A omissão estatal é conduta inadmissível no Estado Democrático de Direito e, por isso mesmo, geradora de responsabilidade em nome do princípio da legalidade.

A manutenção da ordem pública, a garantia dos bens constitucionalmente tutelados e erigidos à condição de direitos fundamentais, são deveres elementares do Estado. A responsabilidade objetiva do Estado face às ações sanitárias (comissivas ou omissivas), caracterizada como causa eficiente e suficiente do dano, não pode ser negada, sob pena de restarem negados os princípios fundamentais do Estado brasileiro, e negar-se, até mesmo, a supremacia da Constituição.

Observa-se assim que o instituto jurídico sob análise trata-se, na verdade, de um eficiente meio de luta colocado ao alcance dos cidadãos que, de outra maneira, ficariam desprotegidos e sujeitos a inúmeras lesōes e abusos resultantes da ação do Poder Público, com o desprezo das garantias individuais básicas do Estado Democrático de Direito, impossibilitando o convívio estável e equilibrado em sociedade do qual o próprio Estado deveria sempre zelar.

A certeza que se tem, no ordenamento jurídico, é de que a responsabilidade do Estado existe como meio de manutenção do equilíbrio social, econômico e jurídico. Caso esse equilíbrio seja quebrado, cabe ao Direito restabelecê-lo.

O que resta considerar, enfim, em tema de complexidade tão acentuada, é que os estudos a respeito da responsabilidade civil do Estado face às açōes de vigilância sanitária ainda são embrionários, se bem que dotados 
de extraordinário sentido de avanço, na direção de se conseguir, a cada passo, maior número de respostas jurídicas eficazes à solução dos conflitos de interesses nascidos na sociedade, buscando-se a materialização do direito à saúde como um todo.

\section{REFERENNIAS}

ARANHA, Márcio lorio; TOJAL, Sebastião Botto de Barros (Orgs.). Curso de Especialização à distância em Direito Sanitário para Membros do Ministério Público e da Magistratura Federal. Brasília: UnB, 2002.

BRASIL. Constituição. Constituição da República Federativa do Brasil. Brasília, DF: Senado, 1988.

. Lei n. 8.080, de 19 de setembro de 1990. Dispõe sobre as condições para a promoção, proteção e recuperação da saúde, a organização e o funcionamento dos serviços correspondentes e dá outras providências. Diário Oficial da República Federativa do Brasil, Brasília, DF, 20 de setembro de 1990. Seção I, pt. I, p. 18055-9.

CAHALI, Yussef Said. Responsabilidade civil do Estado. 1. ed. São Paulo: Malheiros Ed., 1982.

COSTA, Ediná Alves. Vigilância sanitária: proteção e defesa da saúde. São Paulo: Sobravime; Hucitec, 2000.

DI PIETRO, Maria Sylvia Zanella. Direito administrativo. 10. ed. São Paulo: Atlas, 1999.

FIGUEIREDO, Lúcia Valle. Curso de direito administrativo. 2. ed. São Paulo: Malheiros Ed., 1995.

GONÇALVES, Carlos Roberto. Responsabilidade civit. de acordo com o novo Código Civil (Lei n. 10.406, de 10.1.2002). 8. ed. São Paulo: Saraiva, 2003.

MARQUES, Maria Cristina et al. (Org.). Casos e fatos da vigilância sanitária sobre a saúde da sociedade. São Paulo: Sobravime; CVS, 2002.

MEDAUAR, Odete. Direito administrativo moderno. 4. ed. São Paulo: Ed. Revista dos Tribunais, 2000.

MELLO, Celso Antônio Bandeira de. Curso de direito administrativo. 16. ed. São Paulo: Malheiros Ed., 2003.

MENEZES, R. F. de; SILVA, Z. M. da; HORIE, M. H. Y. S. Avanços e recuos: um caso de São Paulo. In: MARQUES, Maria Cristina et al. (Org.). Casos e fatos da vigilância sanitária sobre a saúde da sociedade. São Paulo: Sobravime; CVS, 2002. p. 70-71.

MORAES, Alexandre de. Direito constitucional. 5. ed. São Paulo: Atlas, 1999. 
NEMETZ, Luiz Carlos. Epidemia de dengue - responsabilidade civil. Revista Jurídica Consulex, Brasília, ano 6, v. 124, p. 30-31, mar. 2002.

VENDRAMEL, Aparecida. Responsabilidade extracontratual do Estado. 1. ed. São Paulo: Themis, 2000.

VIGLIAR, José Marcelo Menezes. Saúde pública e improbidade administrativa. In: ARANHA, Márcio lorio; TOJAL, Sebastião Botto de Barros (Orgs.). Curso de Especialização à distância em Direito Sanitário para Membros do Ministério Público e da Magistratura Federal. Brasília: UnB, 2002. 